\title{
El magnetismo del centro peninsular: la configuración del iberismo a través de Miguel Torga y Gaziel
}

\author{
Juan José ORTEGA RoMÁN \\ Universidad Complutense de Madrid \\ jjortega@filol.ucm.es
}

\section{RESUMEN}

Análisis de la obra del portugués Miguel Torga y del catalán Agustí Calvet, Gaziel con el objetivo de intentar vislumbrar en sus libros de viajes las características que configuran el iberismo a lo largo del siglo XX y las relaciones peninsulares entre periferias y centro.

Palabras clave: Comparatismo ibérico, literatura de viajes, iberismo, Torga, Gaziel.

\section{The Magnetism of the Peninsular Centre: The Configuration of Iberism through Torga and Gaziel}

\begin{abstract}
Analysis of Miguel Torga's and Agustí Calvet, Gaziel's travel writing with the purpose of trying to see the characteristics that conforms the iberism along the 20th century and the relationships between peripheries and centre.
\end{abstract}

Keywords: Iberian comparative studies, travel writing, iberism, Torga, Gaziel.

Perdoa-nos a todos, por não termos outra maneira de te ver. Miguel Torga, «Acto de contrição» (Diário V)

\section{Introducción}

Enmascarados con sus respectivos pseudónimos literarios, dos escritores, uno del oriente peninsular y el otro del occidente, arriban al seco dique -castellano por aquel entonces- del capitalino Madrid. Nos referimos al periodista catalán Gaziel (cuyo verdadero nombre es Agustí Calvet i Pasqual), quien, habiéndola visitado 
con anterioridad, vivió en la ciudad en los albores de la década de los cincuenta, y al portugués Miguel Torga (Adolfo Correia da Rocha, médico de profesión), que estuvo en ella en repetidas ocasiones en un periodo que va desde 1937 hasta 1984. Tránsfugas de su propia realidad, cuando no centrífugos de urbes peninsulares de peso -sean Lisboa o Coímbra, sea Barcelona- y víctimas de unas coordenadas espacio-temporales en las que habrían deseado no verse inmersos, ambos autores se abrazan en el iberismo que -con sus propias y respectivas contradicciones- propugna cada uno de ellos. Afirmando su carácter autóctono y sin perder de vista el horizonte que parece terminar a orillas del Mediterráneo, en un extremo, y del Atlántico, en el otro, gerundense y trasmontano, catalán y portugués, lanzan sus miradas al respectivo pueblo hermano separado físicamente por el vasto territorio castellano, si no exactamente geográfico, sí lingüístico. La solución en este caso pasa por acoger un panhispanismo entendido como la suma de todos los pueblos que componen la Península Ibérica. No obstante, en las páginas que siguen, y para no enturbiar esas miradas, conscientes de que la época que vive cada uno y las circunstancias sociopolíticas que atraviesa nuestro país son harto diferentes, nos acercaremos a cada uno de estos dos escritores desde su propia peculiaridad. Sólo en muy contadas y precisas ocasiones se nos hará necesario un apunte conjunto o, cuando menos, comparatista. Será entonces cuando podremos apreciar que si Miguel Torga nos ofrece un panorama que va desde criterios que pasan de lo puramente individual (el afianzamiento de la propia personalidad, la presencia de las pasiones o el gusto por el arte y la literatura como elementos configuradores de un espacio común) a lo universal (la necesidad de que el nacionalismo no se malinterprete allende nuestras fronteras y de que la política no ensombrezca el prometedor panorama que presenta la Península Ibérica), Gaziel dirige su mirada hacia la común historia y hacia una particular y fructífera literatura española como punto de partida de ese iberismo que él pretende encontrar. Vaya por delante, pues, nuestra intención individualizadora.

\section{Miguel Torga}

En plena guerra civil (1937) un desafiante y nada timorato Miguel Torga se adentra en España y la recorre camino de Francia e Italia. El resultado de esos y otros viajes se verá plasmado en sus Diários, así como en otras obras que iremos recogiendo a lo largo de estas páginas. «Me he sentido y me siento muy atraído por España. Yo he llegado a ir a Madrid sólo por ver el Guernica», le confiesa el luso a J. M. Moreiro (1998: 23). Curiosas palabras, porque cuarenta años antes había escrito en Diário VIII «[...] Madrid é a única terra de Espanha de que não gosto» (Torga 1976: 128). Pero no nos llamemos a engaño, ya que no es la ciudad en sí misma, sino su génesis: «[...] porque não consigo esquecer o seu nascimento por fecundação artificial» (Torga 1976: 128). Mucho lo tuvo que atraer y muy grande hubo de ser el amor que sintió por nuestra patria, porque lo cierto es que, como él mismo reconocía, y según señala M. V. Navas Sánchez-Élez (2007: 197), «España es uno de los agentes que impide que Portugal se desarrolle, que reciba culturas de fuera, 
que sea causa y motivo de que esté sometido». Esta atracción, no obstante, no deja de producirle sufrimiento y de antojársele una infidelidad para con su patria. Así, ya en la década de los ochenta declara:

Muitas vezes tenho perguntado a mim mesmo se o meu amor a Espanha não será um sentimento compensatório. A cada passo desconsolado com a pátria que me calhou na rifa da vida, mitigo a frustração cívica numa espécie de adultério platônico. (Torga 1987: 75)

Un «ni contigo ni sin ti», que nos da cumplida cuenta de esa sempiterna contradicción que se refleja en la totalidad de su obra y que, de hecho, le imprime coherencia. Nos hallamos, como señala F. de M. Gonçalves (1987: 124), ante un «espesor de contradicciones coherentes». Y así, encontramos en el escritor un buen ejemplo de pares opuestos que conviven entre sí. Tal cual le sucede a España y Portugal; el iberismo de Miguel Torga no es más que la propia plasmación de su ser, un ser que se debate -recordando al maestro C. Guillén- entre lo uno y lo diverso, entre el blanco y el negro. La continua tendencia maniqueísta acaba las más de las veces en tensión, en conflicto no siempre resuelto. No en vano, P. Vázquez Cuesta (1984: 18) lo considera $«[\ldots]$ criatura bipolar, constantemente dilacerada entre solicitaciones opuestas». Hallándose nuestro escritor en medio, tanto Portugal como España tiran de él en direcciones opuestas. Todo un pulso de iberismo con una victoria $-i$ a favor de quién?- de difícil catalogación.

A Miguel Torga, como en su día hicieran los noventayochistas, le duele España. O mejor dicho: la indiferencia con la que fue tratada por otros países y la ausencia de ayuda en la guerra civil del 36:

As tratantices que o mundo tem feito a esta pobre Espanha! [...] Mil anos que eu viva, nunca perdoarei o cinismo duma França socialista, duma Inglaterra liberal e duma América democrática a contemplarem de palanque o drama da guerra civil, como se estivessem a assistir a uma gigantesca tourada humana. (Torga 1976: 127)

Pero, sobre todo, le duele Portugal. La esencial diferencia tal vez estribe en el hecho de que se pongan los ojos en los territorios vecinos para sacudirse el multisecular polvo de encima. Para mirarse en el espejo del país limítrofe hace falta estar de pie y libre de viejos lastres. Pasados los años, el portugués -en su libro de viajes Portugal (1950)- dará cumplida cuenta de la esperanza que deposita en una nación que -a pesar de tener derrochadores lisboetas, perezosos ciudadanos en Coímbra o campesinos que, ciertamente, muy poco o nada creen en un espíritu reformador- se encuentra unida en su multiplicidad. Quién sabe si gracias a su «insularidad», entendida en términos torguianos: «Este nosso destino portugués! Cercados de mar e de Espanha por todos lados, impedidos de qualquer osmose natural com idéias e culturas alheias [...], aquí nos perdemos num monólogo insular» (Torga 1976: 94). Habiendo conseguido dar el primer paso, Torga amplía el concepto de insularidad y «sonha uma Ibéria, "jangada de pedra" virada para dentro, casa común», como nos recuerda F. Paulouro Neves (2013: 83). 
Y si bien es cierto que, tal y como afirma P. Vázquez Cuesta (1984: 9), el portugués «[...] ha pateado nuestro suelo en una insaciable búsqueda del ser de España», Torga se adentra en España buscando al otro pero también a su yo. Su periplo es un viaje a medio camino entre el de la conquista y la decepción: «Nada conquisto, porque são moinhos / Os gigantes que encontró nos caminos» (Torga 1983: 169). El viajero quiere establecer lazos, lanzar las amarras -desde la marítima Lisboa al árido centro peninsular, a Madrid. Atados los cabos en el noray capitalino y echadas las anclas en un mesetario desierto, la seguridad para moverse por las calles madrileñas está garantizada. En ese viaje real y palpable, pero también de descubrimiento interior, el afianzamiento del yo -y por ende, de la nación portuguesa- pasa por imponerse. Así, nos llega a confesar esa «[...] sensação agradável de alargamento físico, de reconciliação íntima, de fome satisfeita. Parece que se completam em mim não sei que crescimento celular» (Torga 1964: 33). El ejercicio artístico -ya en forma de literatura narrativa, ya bajo la apariencia de diario- acaba desembocando en su propia alma. Miguel Torga, una vez más, ahora en palabras de P. A. Santos (2004: 206) a propósito del libro Portugal, se escribe a sí mismo y transcribe sus propias emociones. En su buceo por nuestras tierras un aire de universalización recorre sus más íntimos deseos. Para él, un nacionalismo mal entendido, rayano en el provincianismo, poco o ningún favor le hace al progreso de un país. De ahí su rechazo a la dictadura del general Franco y a ese tipo de nacionalismo. Ante el saludo de «iArriba Franco!» su respuesta es ésta: «Não. Ao menos eu seria um protesto. A mãe Ibéria cortar-me-ia o braço se, em resposta à provocação arrogante dos funcionarios, o erguesse tambén para saudar um tirano» (Torga 1948: 12). No en vano, Castilla se le antoja una prisión: la de la Fe y de la Patria (Torga 1974: 119). Pero es que, además, esta tierra hace gala de una pasión centrípeta y uniformadora:

Castela a centrípeta, Castela a dominadora, Castela a contraditória... O seu fanático sentido da uniformidade não a deixa tolerar a diversidade; e ese mesmo trágico monolitismo impede-a de entender a fraternidade de corações, de línguas, de paisagens, de destinos... (Torga 1964: 136)

Aun así, no ha conseguido diluir la idiosincrasia de los pueblos ibéricos circundantes que, unidos en la diversidad, han logrado crear todo un bloque espiritual subcontinental:

Uma Ibéria que afirmei convictamente aos meus interlocutores ser um verdadeiro continente, pela singularidade da sua fisionomia física, rácica, idiomática, cultural, económica e política. Mais do que um conglomerado de regiões, um conjunto de nações. [...] Nações unidas pela mesma fatalidade geográfica e por uma teia de cruzamentos históricos, mas tão vincadamente originais que as fronteiras de cada uma, mais do que no mapa, estão traçadas na alma de cada filho. (Torga 1987: 36)

Por eso, como afirma P. Vázquez Cuesta (1984: 19), «Frente a Europa o el mundo [...], España y Portugal -hermanados por fin en una Iberia compartida- se convierten en una base ancestral de hábitos, reacciones y actitud ante la vida». Sólo una vez instalados en ese espacio común se entiende que ambos países «sejam 
patria, não exílio, para portugueses e espanhois», a juicio de J. Herrero (1979: 9). Esta Iberia es, además «Un espacio de tenacidad, de ilusión, de lucidez y de angustia, agitado por mil tormentas y convulsiones, y poblado por seres reales que el tiempo ha ido transformando en fantasmas», como le hace saber el propio Miguel Torga (1986: 12) al lector español. En ese espacio ciclogenético, el «rompeolas de todas las Españas» que es Madrid, representante del centro peninsular -ya que «Madrid estende os braços tentaculares através da planura, na tentativa igualmente dominadora de meter num só redil urbano todos os espanhois vivos, desavindos também» (Torga 1964: 34)- debería ser un plácido lago en el que las aguas no hicieran más que confluir y encontrarse. Sin ningún ímpetu. La paulatina mescolanza sería lo deseable. Pero donde el proyecto torguiano hace aguas - permítasenos seguir con la metáfora y la transposición del conflicto- es, justamente, en la creación de dos bloques que deberían ser tres, cuando no cuatro o cinco. Miguel Torga, contradiciendo sus propias palabras, concibe una sola entidad que abraza a Cataluña y, en un sentido amplio, a Castilla. Realizada la amalgama, un territorio pretendidamente compacto se aúna con Portugal. Craso error. Un error del que es consciente, aunque quizá algo tarde. Estando en Barcelona escribe:

Agora compreendo eu a Catalunha, o seu drama e a sua condenação. Agora percebo eu a razão por que os problemas de Espanha são vistos daqui sob un ângulo particular [...]. Rica e prática, esta gente não entende Castela [...]. Industrioso e sensível, o homem daqui $[\ldots]$ tem pouco que ver com a sombra espectral dum salmantino. (Torga 1974: 125)

Para, acto seguido, decir:

Une-os, contudo, a fatalidade dum matrimónio geográfico, infeliz mas indissolúvel. A natureza, de vez em quando, engánase. Mete dentro da mesma casca uma castanha grande e uma pequenina. Ambas têm a sua camisa individual, mas que importa! Integradas numa só realidade espacial, terão de cumprir juntas sonhos diferentes. (Torga 1974: 125-126)

Que nadie conciba, pues, un regreso a la génesis histórica para vislumbrar los tímidos pasos que llevarían a la creación de una España imperial. El iberismo de Miguel Torga cree en el mantenimiento de la propia personalidad de sus componentes, Portugal incluido. El espacio -tal vez utópico- ibérico vuelve a conformarse gracias a los dos movimientos contradictorios de los que nos hablaba C. C. Rocha Crabbé (1977: 180-185): el progresivo y el regresivo. Abrirse al mundo (al resto de la Península) no significa perder la propia identidad (la de Portugal). El escritor, de hecho, aboga por una misión lingüístico-apostólica confiando en que la lengua portuguesa pueda ser llevada, como antaño, a otros confines: «Língua e cultura que deram a volta ao mundo, e continuam clamorosamente à espera da sua hora europeia» (Torga 1987: 58). Quién sabe si en su más íntimo yo, el trasmontano se contentaba con que fuera (re)conocida en la propia Península Ibérica.

Es muy posible que el problema le venga dado, más que por la realidad, por el lastre que toda una tradición cultural arrastra. Miguel Torga extrapola el carácter de 
un pueblo a la misma esencia del arte; de sus tendencias rezuma una idiosincrasia que muy poco o nada tiene ya que ver con el presente en el que se encuentra instalado. Es lo que se colige de las siguientes palabras: «Num pórtico, num quadro, num poema, espelha-se sempre um país inteiro» (Torga 1983: 142). Para el poeta, nos recuerda J. Herrero (1979: 129), «[...] a patria é cultura. E a cultura que rega o húmus fecundante da sua alma é a cultura ibérica -uma cultura que não aceita limites fronteiriços entre Portugal e Espanha». Tal vez porque para nuestro escritor, siguiendo a M. V. Navas Sánchez-Élez (2009: 543), la relación que existe entre los habitantes de esa realidad llamada Iberia «se establece en el plano de las emociones, de la abstracción, no en el de la razón y el objetivismo». Sirva como muestra el episodio que nos narra en el volumen tercero de A criação do mundo (1937-1981) sucedido en la Pinacoteca de Brera de Milán:

Continuei, contudo, a procurar um nome lusíada nos museus, nas bibliotecas, nos relicários da arte e do pensamento. [...] Quando descobri uma tela de Ribera numa galería, quasi que chorei de emoção. O pintor não nascera em Portugal -José Ribera. Español Valenciano, assinara- mas era peninsular e figurava ali ao lado de Pollaiuolo. (Torga 1948: 62-63)

¿Quiere ello decir que abandona de este modo el pragmatismo para tenderle la mano a un espíritu común que subyace -o flota- en los distintos pueblos ibéricos? Cobran fuerza aquí las palabras de G. Magalhães y F. F. Da Silva (2013: 10): «[...] nuestros autores literarios son los filósofos que nos han tocado: los portugueses piensan soñando y, por ello, proyectan sus reflexiones en las nieblas de la literatura». Consciente de ello o no, lo cierto es que el iberismo de Miguel Torga adquiere unas dimensiones cósmicas y hasta etéreas. La idílica tierra que propone tal vez no sea posible en esta península real y palpable. El espacio supranacional tan solo es realizable en la «indisoluble complicidad humana», en palabras de F. de M. Gonçalves (1987: 132). Pero esta complicidad no es tangible; flota en el aire -o no- y se encuentra por encima de nuestras cabezas. Su tinte filosófico le acerca a postulados espaciotemporales como los que propone, pongamos por caso, la narrativa del rumano Mircea Eliade y obras como su Boda en el cielo (1981).

Miguel Torga, en el prólogo a la edición española de $A$ criação do mundo, le dice al lector:

Antes de nada, quiero presentarme. Soy un portugués hispánico. Nací en una aldea trasmontana, pero respiro todo el aire peninsular. Celoso de mi patria cívica, de su independencia, de su Historia, de su singularidad cultural, me gusta, sin embargo, sentirme gallego, castellano, andaluz, catalán, vasco... (Torga 1986: 11)

Y unas líneas después nos refiere ese espacio idílico que tal vez sólo exista en sus más íntimos anhelos. Es aquí donde Torga se erige en Dios creador y construye un mundo, si no a su semejanza, sí a su imagen:

Fíjate en el título [La creación del mundo]. Significa que tienes ante ti un volumen que narra la génesis progresiva en una conciencia de la realidad circunstancial [...] y 
todos llegamos a nuestro último día con la visión de un mundo creado a nuestra medida. Original y único. El mío es éste. (Torga 1986: 11-12)

Un mundo ibérico que va desde el rendido homenaje que tributa a Miguel de Cervantes (1547-1616) o Miguel de Molinos (1628-1697) -adoptando como parte del pseudónimo el nombre de Miguel- hasta la admiración que siente por José Ortega y Gasset (1883-1955) o, de nuevo, otro Miguel: Unamuno. Miguel Torga intentará plasmar, en torno al casticismo, su particular sentimiento trágico de la vida en esta Iberia invertebrada. Algunos de los títulos de su producción narrativa, dramática o poética giran, en el fondo, en torno a lo mismo; su obra es el cántico de un hombre cuya ansiedad y lamento anhelan un paraíso conformado por la tierra firme que se encuentra en la sinfonía compuesta por un Orfeo rebelde a caballo entre el Océano Atlántico y el Mar Mediterráneo que tanto admira y que tanto lirismo le provoca: «Agora era o Mediterrâneo que solicitava os sentidos. Um Mediterrâneo adormecido e azul, calmo prado sem ondas, onde boiavam felices e seguras todas as ninfas e todas as velas. -Que maravilha de mar!» (Torga 1948: 49).

\section{Gaziel}

Es también Miguel de Unamuno quien sirve de referente y adalid a la hora de compactar las ideas iberistas del noucentista Agustí Calvet. Si ya en Portugal enfora (1960) el catalán tiende un lazo que cruza la Península Ibérica y que aboga -previa y mutua toma de conciencia de la realidad circundante- por el (re)encuentro y hermanamiento de sus pueblos, en obras como La Península inacabada (1961) Gaziel ahonda en las raíces del «[...] adstrato iberista que desde mediados del ochocientos proponía una revisión histórica y una reordenación política del mapa peninsular», siguiendo a J. M. Ribera Llopis (2012: 196). Y si bien Miguel Torga se anclaba en el hipocentro castellano -procedente de un epicentro portugués- para atrincherarse en el bastión iberista, Gaziel salta desde Cataluña para, una vez puestos los pies en Madrid, extender los brazos a quien configura el rostro del mapa ibérico y proclamar su sentir a los cuatro vientos. Cobran sentido aquí, ahora más que nunca, el significado de 'intermediario' y de 'voz de la conciencia' que la palabra 'daimon' tenía en el mundo griego (Juliana 2013: 54). Sólo de este modo, quizás, se sacudirán los cimientos de los territorios que conforman esa parte de Europa separada del resto continental por la cadena montañosa pirenaica. Cerrada la peculiar frontera, y replegada la península sobre sí misma, es precisamente en este aislamiento, desde dentro, donde se da el caldo de cultivo necesario para que los presupuestos iberistas salgan a relucir. Establecida, pues, esta situación, nos atrevemos desde estas páginas a hablar de una «península-isla». Tal vez, por lo anteriormente dicho, sea en Castella endins (1959) donde el escritor asienta las bases de la Trilogia ibèrica. Gaziel, que -recordando a Ortega y Gasset- se lamenta de la deshumanización del viaje (1970: 1110), aprovecha sus desplazamientos para reflexionar y expresar sus ideas y - ¿por qué no decirlo?- para soñar. No en vano la mencionada trilogía conformará, junto a Cura d'aires (1961-1962) la genérica serie Viatges i somnis. Unos sueños 
que se vieron posiblemente alimentados por el cobijo que las propuestas de equiparación del saudosismo portugués y del enyorantisme catalán de Teixeira de Pascoaes le dieron, según nos refiere J. Sala-Sanahuja (2010: 138-139). Y a pesar de que Teixeira renueva, refuerza y extiende sus ideas iberistas por Castilla, con Don Quijote como personaje paladín (Sala-Sanahuja 2010: 138-139), se le olvida hablar a este crítico -creemos- del sentimiento de nostalgia castellana, añoranza de un pasado glorioso, que surge a raíz de la pérdida de las colonias en aras de unir ambas costas marítimas y darle cohesión al amplio territorio peninsular.

Imbuido de un espíritu regeneracionista, Gaziel ve en la ignorancia uno de los principales males que aquejan al hombre. Un hombre que no ha querido ir más allá de lo que su vista alcanza, de su patria chica. Por ello la máxima aspiración del gerundense es «desvetllar l'interès de la gent sobre la nostra Península Ibèrica, tan poc coneguda dels catalans» (1970: 741). Su propósito es que los catalanes «coneguin, comprenguin i estimin la comunitat i la diversitat de la Península Ibèrica» (1970: 742). Sólo conociendo realmente al otro es posible luchar contra la ignorancia, las supersticiones y los tópicos secular y erróneamente establecidos: «Era mentida que Castella hagi de ser, fatalment, només sequedat i aridesa. Tanta de literatura com s'ha fet sobre aquesta eixutor, suposada radical i incurable, reposa damunt una idea falsa» (Gaziel 1970: 747). Instalado en la Castilla más tradicional y haciendo gala de unos conocimientos históricos - que flaco favor le hacen a su intento por derribar tópicos-, el autor abunda en personajes como El Greco, Carlos V, Felipe II, Santa Teresa de Jesús..., buena y nutrida parte del pasado histórico, heroico y hasta imperialista de Castilla. Y como fiel y primer representante de esa tierra se proclama la ciudad de Ávila, «[...] Castella pura, monolítica, i res més» (1970: 750). La Ávila desnuda, sencilla, se erige en antonomasia, cuando no en metáfora, del resto de Castilla. Nada tiene que ver, según el autor (1970: 750), con la imperial Toledo, ni con la monumental Salamanca, ni menos aún con Segovia, «un museu escampat al llarg dels segles». Pero atrapado en su contradicción, el catalán reflexiona y, tras la euforia inicial, nos confiesa unas líneas más abajo: «“Això és enorme”, m’he dit, "però definitivament mort. És impressionant [...]. És un món que no tornarà mai més [...]. Això perdura però no perviu [...]"» (Gaziel 1970: 751). El espejo del iberismo se le rompe en mil pedazos. Y el viaje, que se nos antojaba fructífero ante tan vasto y lejano horizonte, es de ida pero también de vuelta y acaba instalándonos en el mismo punto de partida. Tal vez Gaziel parta de un error de base: el de entender el iberismo proyectado desde una errónea posición para convencer a según qué sectores de la población. Es posible que un iberismo catalanista (de este a oeste en su expansión) que cargara más las tintas en el pueblo catalán, al estilo de Joan Maragall, Enric Prat de la Riba (1870-1917) e Ignasi Ribera i Rovira, hubiera tenido distinta acogida. Pero la historia es la que es y esta opción habría sido tachada de nacionalista catalana y, con toda seguridad, atacada. El Gaziel periodista que «[...] emprà la llengua castellana exclusivament com a instrument utilitari» (Benet 1970: XXIV) parece ignorar que hacer lo mismo con la historia castellana no le reporta los frutos deseados.

Por otra parte, referencias a lugares como Brujas, Flandes, Toledo, o Trujillo, y a hombres como Velázquez, Berruguete, Sancho Dávila, Isabel II o Alfonso XIII no hacen sino alimentar una cierta animadversión por todo aquello que, desde una bur- 
guesía catalana, se ha etiquetado tradicionalmente de «nacionalismo español». El intento es loable, pero probablemente sea el exceso al que el pueblo catalán se ve expuesto el que acaba dando al traste con sus buenas intenciones. Tal prolijidad y sobreexposición, lejos de contribuir a ilustrar, cansa y hastía. No así las repetidas ocasiones en las que difunde palabras castellanas (españolas) como 'ventas' (746), 'merenderos' (746), 'juerga' (746), 'arrieros' (750), 'caballeros' (754), 'toreros' (762), 'redil' (777), 'dehesa' (779), 'quintos' (783) o 'botijo' (807)1. Y lo mismo sucede, en Cercant llum i camí, la cuarta parte de Tots els camins duen a Roma (1958), con la capital. El Madrid más castizo hace acto de presencia de la mano de vocablos como 'churros' (583), 'zarzueleros' (583), 'saineteros' (583), 'mantón' (583), 'manolas' (583), 'requiebro' (583), 'verbenas' (586), 'mentideros' (586), 'señorito' (589) o 'chulo' (589), cuando Gaziel se encuentra estudiando allí en las postrimerías de 1908 y tiene ocasión de acudir a los famosos cafés con tertulia y ver a Don Marcelino (Menéndez Pelayo) y Don Santiago (Ramón y Cajal, 1852-1934). De este modo nos describe las impresiones que la capital le produce:

Era, a més, un dels pobles amb sabor autèntic [...]. Madrid era tan lluny de tota altra realitat peninsular, i es trobava tan aillat del món, en el seu alt i ample desert de terres planes, que per força la fesomia moral dels madrilenys havia de ser original. Allò no comunicava, pràcticament, amb res. (Gaziel 1970: 582)

Es esa lejanía de la otra realidad peninsular, así como su altura y altiplanicie mesetaria, las que llevan a etiquetar a Madrid de 'tibetano', de 'techo de España'. Gaziel, además, es de la opinión de que la ciudad forma un mundo aparte y aislado del resto de los territorios colindantes. Siendo la capital y estando abierta a recibir y acoger en su seno a cuantas tendencias y personas se le acercan, lo cierto es que la metrópoli vive ignorante y de espaldas a los pueblos que la circundan. Con su propia particularidad, Madrid es, paradójicamente, una isla dentro de ese desierto que parece ser Castilla y, por ende, el resto de la península. No ha de extrañarnos que, una vez más, los extremos se atraigan; y así entendemos con J. M. Ribera Llopis (2012: 204) que se produzca «una identificación casi automática entre Lisboa y Barcelona que conlleva la implícita diferenciación de Madrid, corte y capital ajena al moderno concepto de urbe económicamente activa».

Gaziel quiere, a toda costa, comprender -de Norte a Sur y de Este a Oeste- nuestra Península Ibérica. Fruto de esa voluntad es su ensayo Enteniment de la Península Ibèrica (1963), publicado originalmente como prólogo a la edición española de Castella endins. En un tono más serio, alejado ya de sus viajes y sueños, el catalán ahonda en la génesis de nuestra propia y común historia (Portugal, Castilla y Aragón, hermanos nacidos de la misma madre) para defender un hermanamiento y escuchar, al unísono, «el cant de les sirenes atlàntiques i mediterrànies» (Gaziel 1970: 1090). La misma sinfonía que quería escuchar Miguel Torga. A Gaziel le habría gustado que

${ }^{1}$ La referencia paginada de todos estos términos responde a la edición citada a lo largo de este capítulo (Gaziel 1970). 
ambas costas pertenecieran a un pueblo con un mismo sentimiento unitario común. A propósito de la frontera que separa España y Portugal - esa península rota, inacabadanos dice: «poques vegades la insensatesa humana haurà establert una ratlla més falsa» (Gaziel 1970: 1091). Su máxima parece ser la de «unir, no separar». También en lo que se refiere a la actual configuración del Estado español. Gaziel, con un tono y un espíritu mucho más teóricos y quizás menos anecdóticos que Miguel Torga, reconoce la idiosincrasia y las particularidades de cada región -ahí reside la riqueza y el orgullo, nada pretencioso y exento de toda vanidad, de pertenecer a un pueblo multilingüe, variopinto en tradiciones, diverso en costumbres, diferente en carácter...-, pero a la hora de hablar de la segregación se nos presenta reacio. Sirvan sus palabras para ilustrar un pensamiento cuando menos sorprendente:

Catalunya és una ínclita nació medieval, d'origen pirinenc i carolingi, sense prou esperit ni empenta per a poder ni saber mai encarnar-se en un cos estatal propi. Hi ha un poble català i una llengua catalana; hi ha uns territoris, una història, una senyera, un caràcter, una cultura catalans. El que mai no s'ha vist encara és un Estat independent que s'anomenés Catalunya. I aquest fet resum ell sol ensems la grandesa i la servitud dels catalans. Perquè enclou el passat, el present i -jo em penso- l'esdevenidor de Catalunya. (Gaziel 1970: 1093)

Se puede colegir de sus palabras, como el propio autor afirma unas páginas después, que Castilla mantiene su primacía como forjadora de la unidad española, cosa que es punto de partida de una polémica que llega hasta nuestros días y que es motivo de ofuscación -las más de las veces sin consenso ni respuestas que satisfagan ni a unos ni a otros- de políticos, pensadores, escritores, ideólogos e historiadores. Y tal vez la solución, o cuando menos, la comprensión y el entendimiento, nunca ha estado tan cercana como en el simple hecho de formular correctamente una sencilla pregunta: «quina unitat?, i [...] quina Espanya?» (Gaziel 1970: 1095). Gaziel nos ha dado las claves en los propios títulos de sus obras: para entender la Península Ibérica hay que comprender que es una península inacabada. Un proyecto inacabado. A caballo de los siglos XV y XVI, Castilla -y en absoluto Gaziel la culpa por ello- se lanza a la conquista de tierras externas y extremas (movimiento centrífugo) en vez de consolidar los territorios internos y próximos (movimiento centrípeto). Y lo mismo sucedió con Portugal. Con Aragón absorbido ya por Castilla, Cataluña «[...] caigué en un abaltiment morbós, només interromput per atacs de deliri» (Gaziel 1970: 1095). Lejos ya del ferviente patriotismo de una España restringida, al igual que hicieran Antoni Maura (1853-1925) o Francesc Cambó (1876-1947), los sueños iberistas de Gaziel comulgan así con los postulados de un último y abatido Joan Maragall que acaba entendiendo que el único ideal posible en esa empresa quimérica toma realidad en un imaginario común, ibérico (Gaziel 1970: 1102). Panibérico -valga la redundancia- añadimos nosotros. Se produce así el paso de la España restringida a la España -latu sensu- soñada. Abandonemos las propuestas medievales y nacionalistas de tinte romántico y aboguemos por una entidad supranacional que abrace un conglomerado de pueblos que poseen más cosas comunes que diferentes. Sólo así la Península se verá completada. 